\title{
Optimization of nebulized delivery of linezolid, daptomycin, and vancomycin aerosol
}

This article was published in the following Dove Press journal:

Drug Design, Development and Therapy

12 August 2014

Number of times this article has been viewed

\section{Paul Zarogoulidis' \\ loannis Kioumis' \\ Sofia Lampaki' \\ John Organtzis' \\ Konstantinos Porpodis' \\ Dionysios Spyratos' \\ Georgia Pitsiou' \\ Dimitris Petridis ${ }^{2}$ \\ Athanasia Pataka' \\ Haidong Huang ${ }^{3}$ \\ Qiang $\mathrm{Li}^{3}$ \\ Lonny Yarmus ${ }^{4}$ \\ Wolfgang Hohenforst- \\ Schmidt ${ }^{5}$ \\ Nikolaos Pezirkianidis ${ }^{6}$ \\ Konstantinos Zarogoulidis' \\ 'Pulmonary Department-Oncology Unit, \\ "G Papanikolaou" General Hospital, \\ Aristotle University of Thessaloniki, \\ Thessaloniki, Greece; ${ }^{2}$ Department of Food \\ Technology, School of Food Technology \\ and Nutrition, Alexander Technological \\ Educational Institute, Thessaloniki, Greece; \\ ${ }^{3}$ Department of Respiratory Diseases, \\ Shanghai Hospital, II Military University \\ Hospital, Shanghai, People's Republic \\ of China; ${ }^{4}$ Division of Pulmonary and \\ Critical Care Medicine, Johns Hopkins \\ University, Baltimore, MD, USA; ${ }^{5}$ II Medical \\ Department, "Coburg" Regional Hospital, \\ Coburg, Germany; ${ }^{\circ}$ Surgery Department, \\ Private Cabinet, Serres, Greece}

Correspondence: Paul Zarogoulidis

Pulmonary Department,

"G Papanikolaou” General Hospital,

Aristotle University of Thessaloniki,

Thessaloniki 55236, Greece

Tel +30 23I 0340370

Fax +30 2130992433

Email pzarog@hotmail.com
Background: At this time, several antibiotics have been investigated as possibilities for aerosol administration, but local therapy has been found to be more efficient in several diseases.

Materials and methods: The drugs linezolid (Zyvox), vancomycin (Voncon), and daptomycin (Cubicin) were tested with three jet nebulizers with seven different residual cups and different loadings. Moreover, three ultrasound nebulizers were again tested with these drugs, with different loadings and mouthpiece attachments.

Results: When drugs are combined with particular cup designs, they significantly lower the droplet size to 1.60 and $1.80 \mu \mathrm{m}$, which represents the best combination of Zyvox and cup G and Cubicin and cup D, respectively. Cup design D is suggested as the most effective cup for lowering the droplet size $(2.30 \mu \mathrm{m})$ when considering a higher loading level $(8 \mathrm{~mL})$.

Conclusion: Modification of current drugs from dry powder to solution is possible, and the residual cup design plays the most important role in droplet size production when the nebulization systems have the same properties.

Keywords: vancomycin, linezolid, daptomycin, aerosol, jet nebulizers, ultrasound nebulizers

\section{Background}

The respiratory system has been a target for local therapies for many years. Several drugs for systemic diseases are currently being investigated for aerosol administration. ${ }^{1-7}$ The respiratory system has several defense mechanisms that the aerosol droplets or dry powder have to bypass in order to deposit in the alveoli. ${ }^{8}$ The beating cilia, mucus, and macrophages are the most important obstacles. The function of beating cilia, macrophages, and mucus production is modified according to underlying respiratory diseases. Chronic obstructive pulmonary disease, cystic fibrosis, and asthma disable the efficiency of the defense mechanisms. Moreover, the thick mucus disables the absorption of deposited drugs. ${ }^{9}$

The lung surface is more than $100 \mathrm{~m}^{2}$, and therefore the absorption of the aerosol drugs through the vessels of the alveoli is fast. ${ }^{10}$ There are several factors that influence aerosol droplet production, and the most important ones can be summarized as follows: jet nebulizer flow rate, ${ }^{11}$ design of the residual cup, ${ }^{12}$ residual cup filling on initiation of nebulization, ${ }^{13}$ residual cup loading, ${ }^{14}$ charge of the drug molecules, ${ }^{15}$ tapping of the residual cup during nebulization, ${ }^{13,16}$ chemical formula, ${ }^{17,18}$ viscosity, ${ }^{11}$ surface tension, and concentration of drug solution.

Other factors affecting the droplet size after production can be summarized as the following: humidity within the airway environment, airway turbulence, 
architecture of aerosol droplet, and temperature within the airways. ${ }^{17,19-21}$ The salts within the chemical structure of the drug formulation are responsible for the absorption of water from the environment and expansion of the molecule. The dry powder as a form of drug administration absorbs water from the environment according to the porosity of the particles, and further hydration may cause either "expansion" or "contraction" of the molecule. The shape of the dry powder particle plays an important role in the induction of cough. If one axis of a dry powder particle is more extensive, the mucosa of the respiratory system will be irritated and cough will be induced. However, the inhaled droplets/particles should not exceed $5 \mu \mathrm{m}$ in size to reach the alveoli. ${ }^{22}$

The major differences between aerosol administration and dry powder administration include the time of aerosol production. Inhaled insulin was one of the first drugs administered percutaneously and transformed so it could be administered as an aerosol. ${ }^{23}$ There has been extensive investigation regarding the safety of aerosol administration of systemic therapies. ${ }^{24,25}$ The knowledge gained from inhaled insulin indicates that an underlying respiratory disease/exacerbation of this disease or respiratory tract infection changes the systemic absorption of an aerosol-administered drug. ${ }^{23}$ In recent years, extensive investigation with inhaled antibiotics has been performed, and there are already several products on the market. ${ }^{6,7}$ Moreover; experimentation has been made to enhance aerosol drug delivery. ${ }^{26}$ In our current research, we investigated whether daptomycin, vancomycin, and linezolid could be administered as an aerosol with jet nebulizers or ultrasound nebulizers, and which could be the optimal combination of residual cup design and residual cup loading.

\section{Materials and methods \\ Drugs}

The following drugs were used: vancomycin hydrochloride 500 mg per vial (Voncon; Hospira Inc., Lake Forest, IL, USA), daptomycin $500 \mathrm{mg}$ per vial (Cubucin; Novartis International AG, Basel, Switzerland), and linezolid (Zyvox; Pfizer, Inc., New York, NY, USA), supplied as a ready-touse sterile isotonic solution for intravenous infusion. Each milliliter contains $2 \mathrm{mg}$ linezolid. Inactive ingredients are sodium citrate, citric acid, and dextrose in an aqueous vehicle for intravenous administration. The sodium $\left(\mathrm{Na}^{+}\right)$content is $0.38 \mathrm{mg} / \mathrm{mL}$ ( $5 \mathrm{mEq} / 300 \mathrm{~mL}$ bag, $3.3 \mathrm{mEq} / 200 \mathrm{~mL}$ bag, and $1.7 \mathrm{mEq} / 100 \mathrm{~mL}$ bag).

\section{Aerosol production systems}

\section{Jet nebulizers and residual cups}

Three jet nebulizers were chosen from our department for the experiment: MaxiNeb ${ }^{\circledR}$ (Flexicare Medical Ltd, Mountain Ash, UK; 6 L/minute and 35 psi), Sunmist ${ }^{\circledR}$ (DeVilbiss Health Care, Inc., Somerset, PA, USA; 5-7 L/minute and 35 psi), and Invacare ${ }^{\circledR}$ (DeVilbiss Health Care, Inc.; 4-8 L/minute and 36 psi; Figure 1).

In total, seven residual cups were chosen for evaluation, four with a capacity of no more than $6 \mathrm{~mL}$, and three with a capacity of no more than $10 \mathrm{~mL}$. The designs for the large residual cups will be mentioned as A, D, and E (Figure 2). The small residual cups will be mentioned as B, C, F, and G (Figure 3) The large residual cups were not used with a capacity of more than $8 \mathrm{~mL}$, as explained in the Discussion. The residual cup loadings were $2,4,6$, and $8 \mathrm{~mL}$ ( $8 \mathrm{~mL}$ only for large cups).

\section{Ultrasound nebulizers}

Three ultrasound nebulizers were chosen from the market (Figure 4). The first was NE-U07 (Omron, Kyoto, Japan). Compact and weighing less than $350 \mathrm{~g}$, it includes a $10 \mathrm{~mL}$ medication cup and generates uniform micro-sized vapor particles. The second ultrasound nebulizer was a portable EasyNeb $^{\circledR}$ II (Flaem Nuova, Martino, Italy), with the following operating specifications; drug maximum capacity, $8 \mathrm{~mL}$; frequency, $2.4 \mathrm{MHz}$; nebulization capacity (adjustable), $0-0.7 \mathrm{~mL} /$ minute approximately (tests performed with saline $0.9 \%$ ); particle size, $2.13 \mu \mathrm{m}$ mass median aerodynamic diameter (MMAD); sound level at $10 \mathrm{~cm}, 50 \mathrm{db}$; operating temperature, minimum of $10^{\circ} \mathrm{C}$, maximum of $40^{\circ} \mathrm{C}$; and air humidity, minimum of $10 \%$, maximum of $95 \%$ relative humidity. The third ultrasound nebulizer was a portable

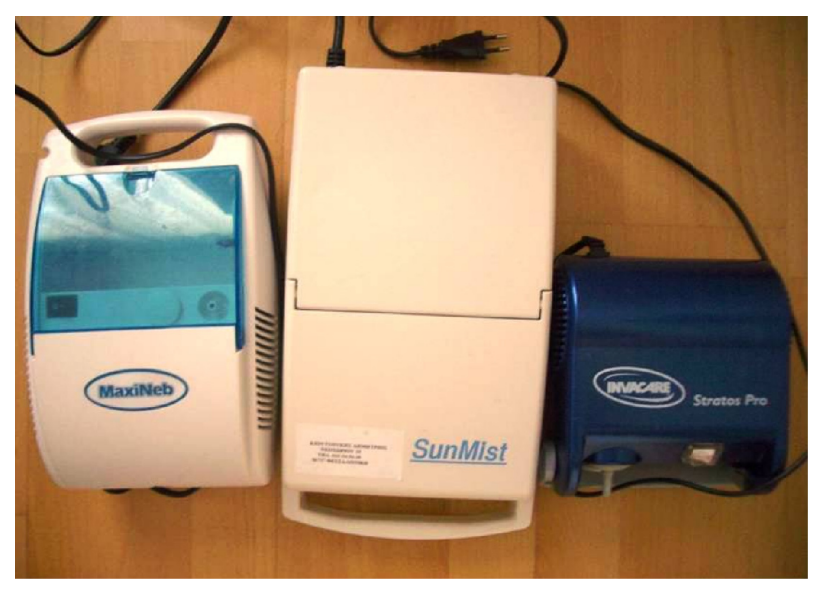

Figure I Jet nebulizers. 


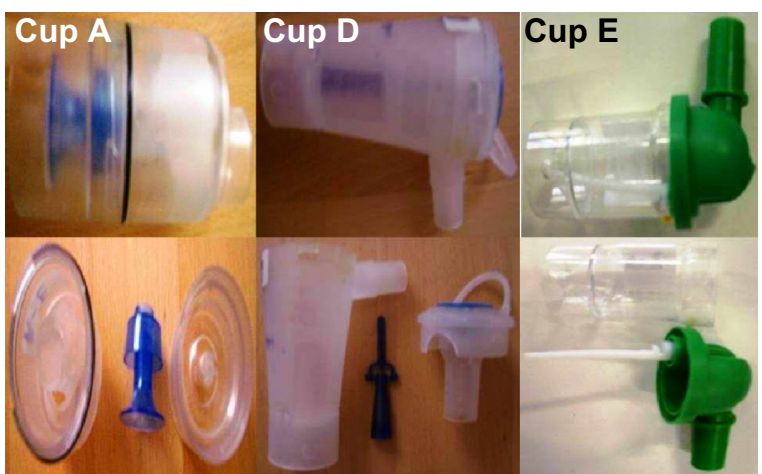

Figure 2 Large residual cups.

GIMA, Gessate, Italy (Choice Smart Health Care Company Limited, Wan Chai, Hong Kong, No G2061259328002) with the following operating specifications: particle size, $3-5 \mu \mathrm{m}$; frequency, $2.5 \mathrm{MHz}$; medication cup capacity, $1-6 \mathrm{~mL}$; sound level at $10 \mathrm{~cm},<50 \mathrm{db}$; operating temperature, minimum of $10^{\circ} \mathrm{C}$, maximum of $40^{\circ} \mathrm{C}$; and air humidity, minimum of $10 \%$, maximum of $95 \%$ relative humidity. The loadings were 2 and $4 \mathrm{~mL}$, as this was the amount of the residual cup for each of the three ultrasound nebulizers.

\section{Droplet measurement}

The size distribution of the droplets and their mean diameter $\left(d_{32}\right)$ were calculated using a Malvern Mastersizer 2000 apparatus (Malvern Instruments Ltd, Malvern, Worcestershire, UK; Figure 5), equipped with a Scirocco module (Malvern Instruments Ltd). The device has been modified to be able to spray the generated droplets directly perpendicular to the laser beam. ${ }^{6,26-29} \mathrm{~A}$ refractive index of 1.33 has been used for the sprayed droplets. The measurements were made under ambient temperature.

\section{Milling}

The daptomycin and vancomycin powders were milled in a planetary ball mill (Pulverisette-5; Fritsch, Idar-Oberstein,

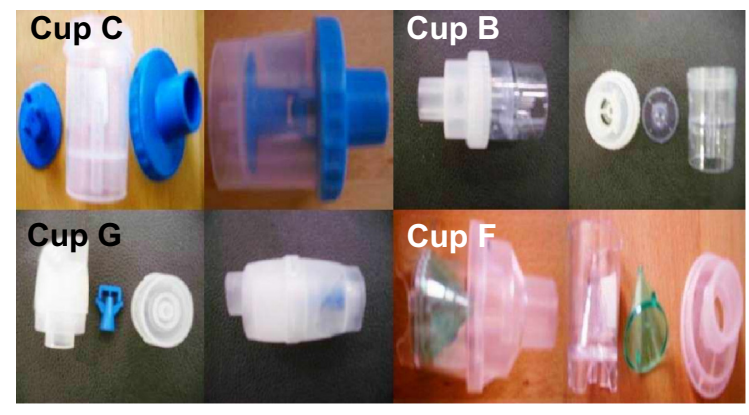

Figure 3 Small residual cups.

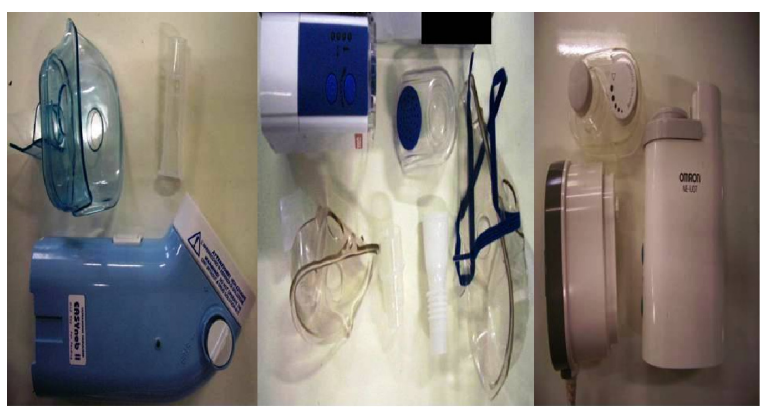

Figure 4 Ultrasound nebulizers.

Germany) equipped with Agate bowls $(500 \mathrm{~mL})$ and 6 balls $(20 \mathrm{~mm}, 20 \mathrm{~g})$ with a rotational speed of approximately $200 \mathrm{rpm}$, which results in an acceleration of about $7.5 \times \mathrm{g}$. We initiated our milling at 120 minutes and acquired a MMAD of $5 \mu \mathrm{m}$ or less (measured with the Mastersizer 2000). After milling, we collected powder of the same weight from each drug and diluted it with $2 \mathrm{~mL} 0.9 \% \mathrm{NaCl}$ in an effort to simulate a future method/compound of administration.

\section{Statistical analysis}

Data (MMAD) were treated using analysis of variance (ANOVA) three times, depending on the fixed factors and their particular levels employed each time. A four-way ANOVA included three Gram-positive antibiotics (Zyvox, Voncon, Cubicin), three nebulizers (Invacare, Sunmist, MaxiNeb), and seven residual cups (A-G) at three loading levels $(2,4$, and $6 \mathrm{~mL})$. A three-way ANOVA included the same drugs and nebulizers and those cups (A, D, E) that could receive a higher load of $8 \mathrm{~mL}$. A four-way ANOVA was finally resumed concerning the same drugs but three unique ultrasound devices (EasyNeb ${ }^{\circledR}$ II, Gima, NE-U07; Figure 4) adapted with two different mouthpieces (inlets 1 and 2) and at two loading levels ( 2 and $4 \mathrm{~mL}$ ).

Statistically significant factors were checked for particular differences between level and interaction means by comparing the $95 \%$ confidence intervals of means.

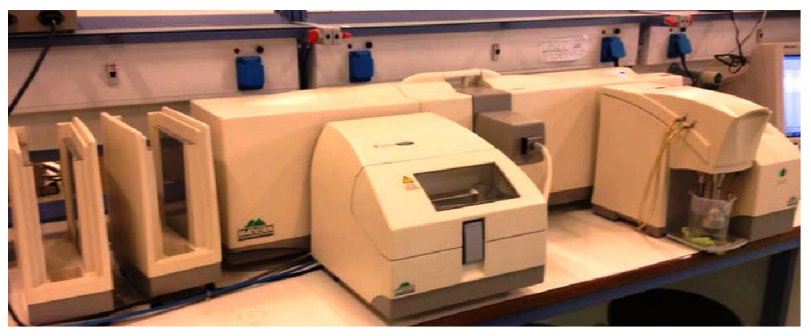

Figure 5 Mastersizer 2000 (Malvern Instruments Ltd, Malvern, Worcestershire, UK). 
Means whose intervals do not overlap differ significantly. The probability of 0.05 was chosen as the reference level of statistical significance.

Normality and homogeneity of the ANOVA residuals were tested in parallel.

Thus, the basic differences among the three ANOVA schemes are the inclusion of residual cups, the $8 \mathrm{~mL}$ loading, and the mouthpiece effect on ultrasound nebulizers.

\section{Results}

Regarding the inclusion of residual cups, ANOVA results revealed statistically significant effects for drugs $(F=3.65$; $P=0.033)$, residual cups $(F=5.442 ; P=0.0002)$, and the interaction term drug $\times$ residual cup $(F=4.045 ; P=0.0002)$. Judging from the $95 \%$ confidence intervals of the drug means, it appears that both antibiotics, Zyvox $(2.88 \mu \mathrm{m})$ and Cubicin $(2.82 \mu \mathrm{m})$, provide a smaller droplet size than that of Voncon $(3.27 \mu \mathrm{m})$.

Cup designs D $(2.67 \mu \mathrm{m}), \mathrm{A}(2.40 \mu \mathrm{m})$, and $\mathrm{G}(2.63 \mu \mathrm{m})$ reduce the droplet size more than the other cups (Figure 6), although the confidence intervals do not differentiate their effects clearly. These effects, however, are better clarified when the interactive results are shown (Figure 7). In fact, cup designs $\mathrm{D}(1.80 \mu \mathrm{m})$ and $\mathrm{G}(1.60 \mu \mathrm{m})$ perform best in droplet reduction when combined with Cubicin and Zyvox administration, respectively.
At higher load (8 mL), ANOVA's statistically significant differences are found only among residual cups ( $F=5.290$; $P=0.034)$, with cup D appearing the most effective $(2.30 \mu \mathrm{m}$; Figure 8).

The mouthpiece does not influence the performance of the device, neither the loads nor the ultrasound nebulizers. Only the antibiotics perform slightly differently $(F=7.028$; $P=0.049)$ because of the smaller droplet size $(2.92 \mu \mathrm{m})$ produced by Cubicin (Figure 9), which gives a result similar to that of Figure 10.

To summarize, Gram-positive antibiotics do not lower the droplet size as effectively as other drugs do, even if they are of different natures in terms of synthesis. ${ }^{6,26}$ Nevertheless, when drugs are combined with particular cup designs, they significantly lower the droplet size down to 1.60 and $1.80 \mu \mathrm{m}$, which represent the best combination between Zyvox and cup G, and Cubicin and cup D, respectively.

Cup design D is suggested as the most effective cup for lowering the droplet size $(2.30 \mu \mathrm{m})$ when considering a higher loading level $(8 \mathrm{~mL})$.

\section{Discussion}

The major findings of our study indicate that cup designs $\mathrm{D}$ $(2.67 \mu \mathrm{m}), \mathrm{A}(2.40 \mu \mathrm{m})$, and $\mathrm{G}(2.63 \mu \mathrm{m})$ reduce the droplets more than the other cups. In fact, cup designs D $(1.80 \mu \mathrm{m})$ and $\mathrm{G}(1.60 \mu \mathrm{m})$ perform best in droplet reduction

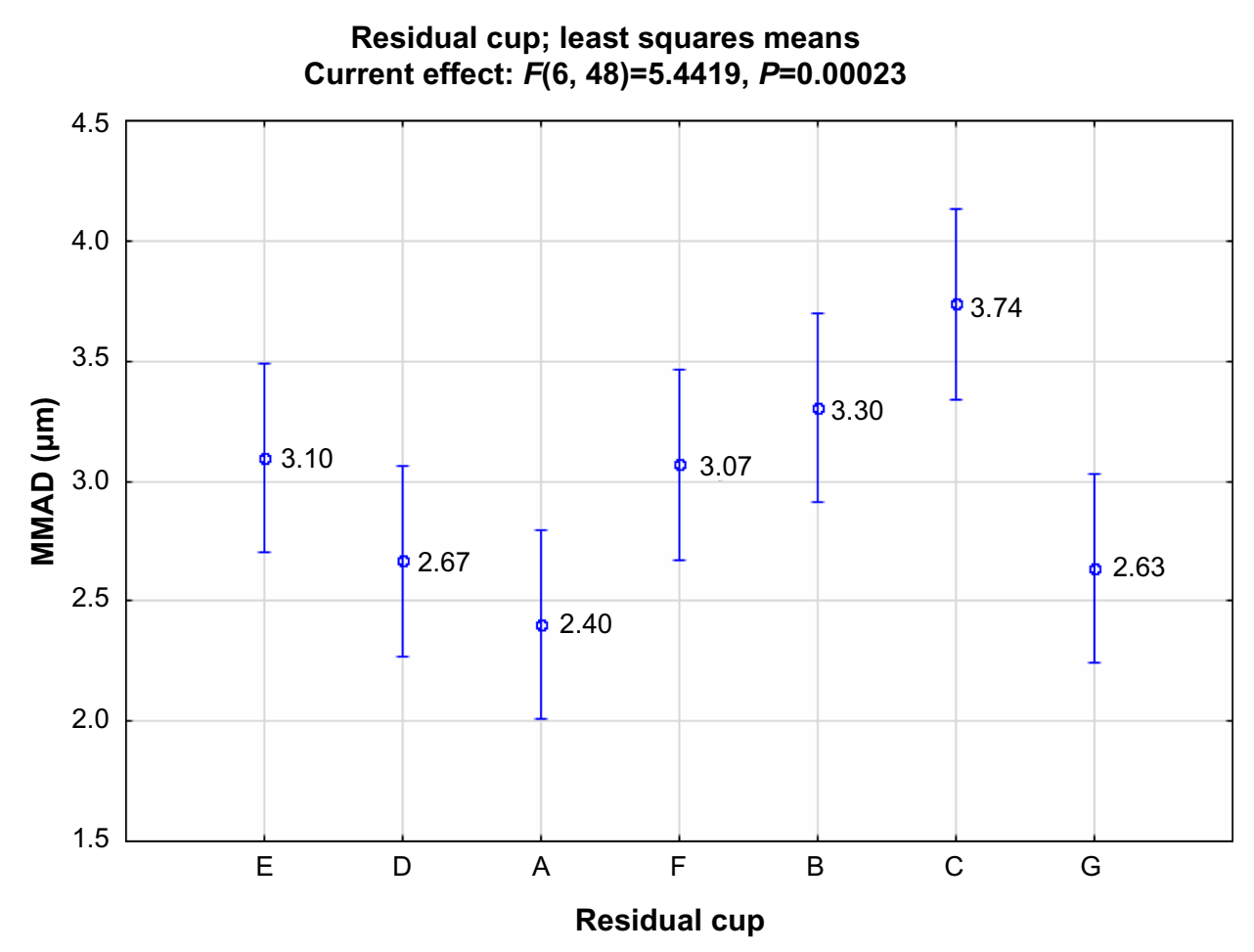

Figure 6 Residual cups and mass median aerodynamic diameter (MMAD) $(F=6,48)$. 
Drug $\times$ Residual cup; least squares means

Current effect: $F(12,48)=4.0451, P=0.00024$

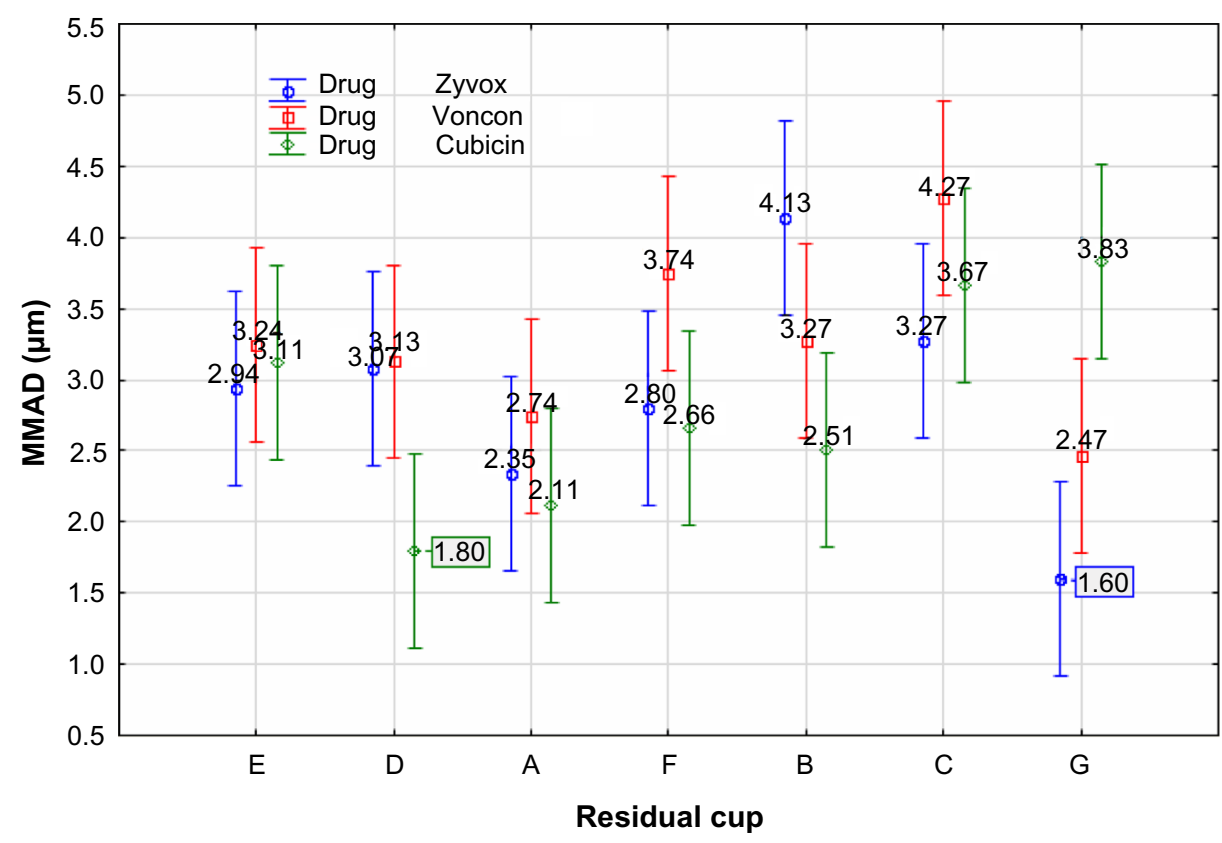

Figure 7 Residual cups, mass median aerodynamic diameter (MMAD), and drugs.

when combined with Cubicin and Zyvox administration, respectively.

At higher load ( $8 \mathrm{~mL}$ ), ANOVA's statistically significant differences are found only among residual cups $(F=5.290$; $P=0.034$ ), with cup D appearing to be the most effective $(2.30 \mu \mathrm{m})$.
The mouthpiece does not influence the performance of the device, neither the loads nor the ultrasound nebulizers. Only the antibiotics perform slightly differently $(F=7.028$; $P=0.049)$ because of the smaller droplet size $(2.92 \mu \mathrm{m})$ produced by Cubicin (Figure 3), which gives a similar result to that of Figure 6. In conclusion, the produced droplet size

Residual cup; least squares means

Current effect: $F(2,8)=5.2896, P=0.03438$

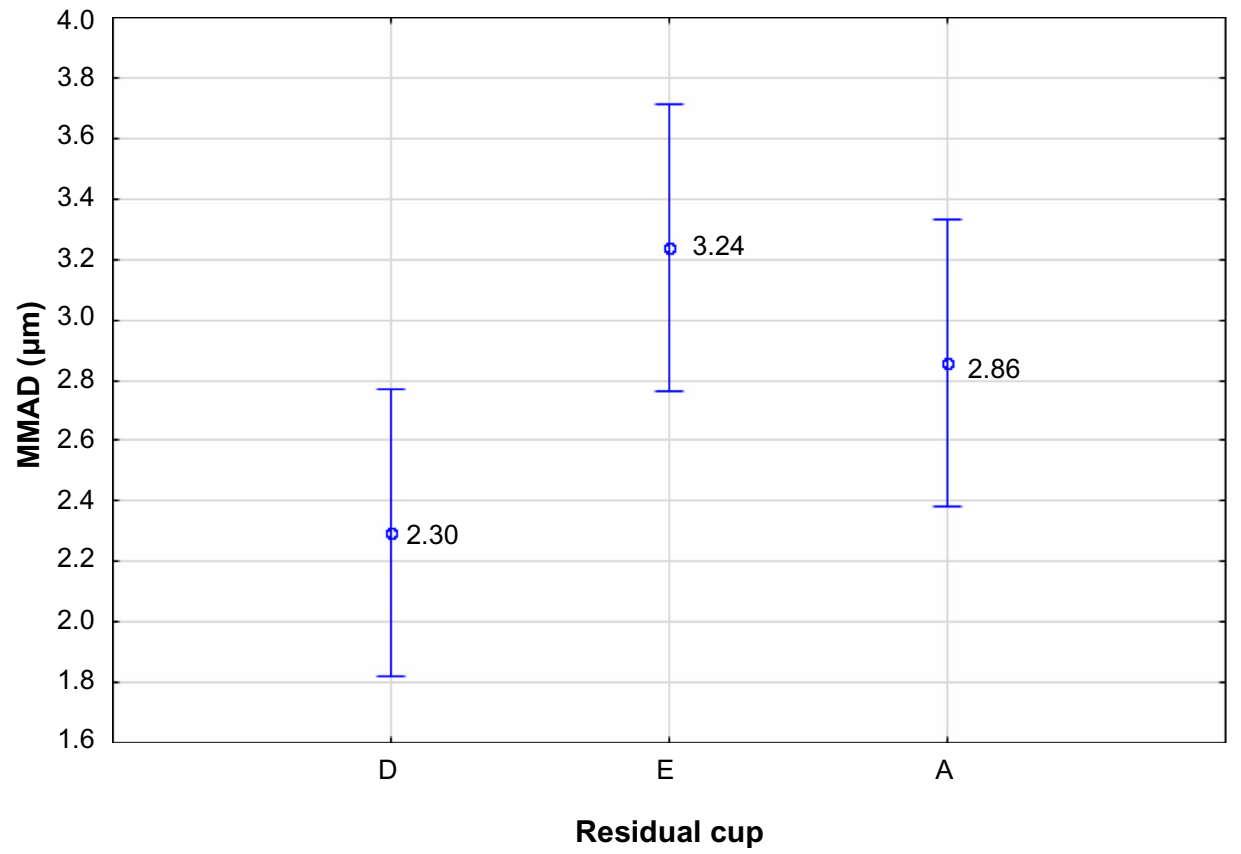

Figure 8 Large residual cups and mass median aerodynamic diameter (MMAD) $(F=2,8)$. 
Drug; least squares means

Current effect: $F(2,4)=7.0276, P=0.04908$

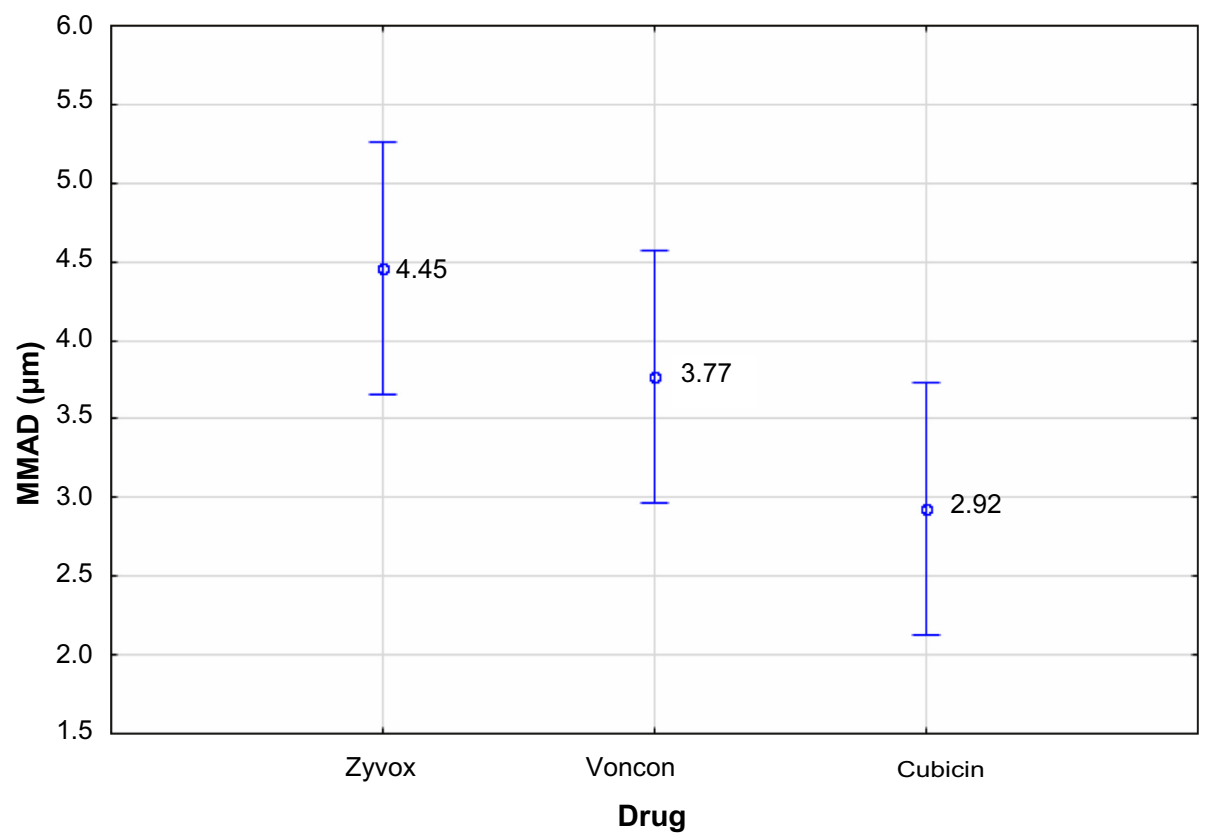

Figure 9 Drugs and mass median aerodynamic diameter (MMAD) $(F=2,4)$.

depends again on particular cup designs (D and G, which are large cups). These larger cups significantly lower the droplet size down to 1.60 and $1.80 \mu \mathrm{m}$, which represent the best combination between Zyvox and cup G, and Cubicin and cup D, respectively. Moreover, the composition of the formulation plays a crucial role. Therefore, several more experiments with different $0.9 \% \mathrm{NaCl}$ residual cup fillings will probably reduce droplet size even more.

Major limitations of our study include, first, the fact that we did not extensively investigate the dilution of different drugs with powder, and we did not measure the time until the residual cup was empty.

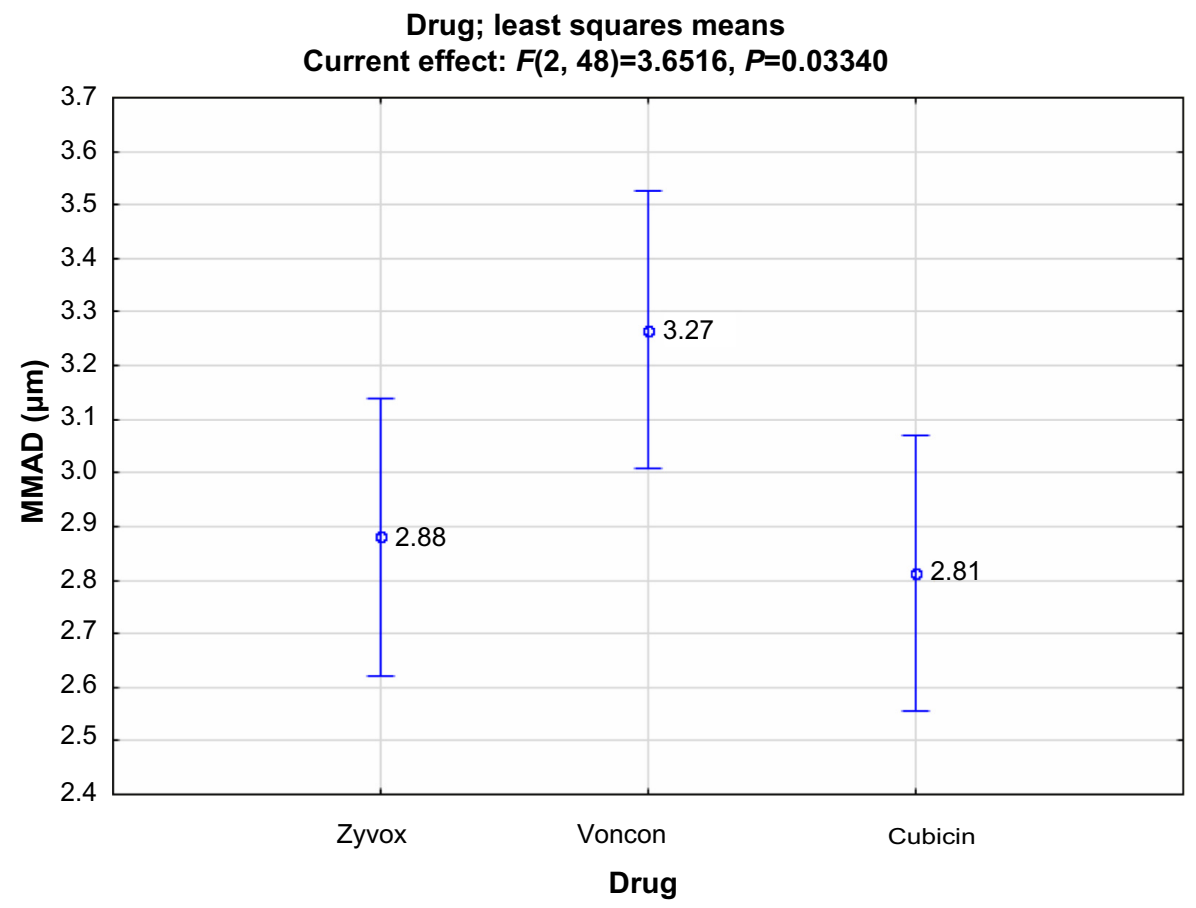

Figure 10 Drugs and mass median aerodynamic diameter (MMAD) $(F=2,48)$. 
Until now, several antibiotics have been investigated for aerosol administration (eg, meropenem ${ }^{6}$ ), and several others are on the market with aerosol administration (eg, tobramycin ${ }^{7}$ ). The optimal combination of nebulization system, residual cup, and loading have also been investigated. ${ }^{11}$ It has also been investigated whether mouthpiece design influences droplet size after nebulization of the solution. ${ }^{26}$

In our current research, we investigated daptomycin, linezolid, and vancomycin. There are no previous studies regarding linezolid or daptomycin; however, there has been experimentation with the aerosol administration of vancomycin. ${ }^{30}$ In the study by Maiz et al, ${ }^{30}$ aerosolized vancomycin was investigated for the first time as a treatment option for patients with cystic fibrosis. It was observed that this method of treatment was safe and well-tolerated and did not induce bacterial resistance. In a study by Park et al, ${ }^{31}$ multifunctional controlled-release nanoparticles of vancomycin were produced as a dry powder.

Future usage of vancomycin in in vivo models will allow us to investigate the superiority of this formulation when compared with normal aerosol. ${ }^{31}$ In the study by Nettey et al, ${ }^{32}$ microspheres of albumin loaded with vancomycin were produced and demonstrated superiority when compared with the solution form. There are several successful examples in which systemic administration of a drug was converted to aerosol; this is the case with insulin and tobramycin. ${ }^{23,33}$ The lesson that was learned was that in the case of insulin, when exacerbation of an underlying disease occurred or when respiratory infection occurred, the dosage administration had to change and glucose measurements had to be more frequent. In fact, the pharmacokinetics of the drug changed because of the alteration of the absorption from the alveoli to the systemic circulation. In contrast, tobramycin was approved for children older than 6 years who had cystic fibrosis. Tobramycin was not approved for acute cystic fibrosis exacerbation or for non-cystic fibrosis patients. ${ }^{34}$

The three antibiotics are effective against Gram-positive bacteria. Linezolid is a member of the oxazolidinone class of drugs. Linezolid has been observed to be active against most Gram-positive bacteria that cause disease, including streptococci, methicillin-resistant Staphylococcus aureus, and vancomycin-resistant enterococci. ${ }^{35}$ The main indications of linezolid until now have been infections of the skin and soft tissues and pneumonia (particularly hospital-acquired pneumonia); however, off-label uses for a variety of other infections are already becoming popular. Linezolid is a completely synthetic drug that does not occur in nature and was not developed by building on a naturally occurring skeleton. After several efforts, there is now a cost-effective method of production. ${ }^{36}$
Vancomycin is a naturally occurring antibiotic made by the soil bacterium Actinobacteria species Amycolatopsis orientalis. The original indication for vancomycin was for the treatment of penicillin-resistant $S$. aureus, a use kept alive for many years by the fact that the compound had to be given intravenously. Vancomycin has been observed to be nephrotoxic and ototoxic; moreover, vancomycin-resistant organisms are becoming common. Therefore, vancomycin is being replaced in the clinical practice by newer antibiotics such as linezolid (Zyvox), daptomycin (Cubicin), and quinupristin/dalfopristin (Synercid). ${ }^{37}$

Daptomycin is a lipopeptide antibiotic used in the treatment of systemic and life-threatening infections caused by Gram-positive organisms. It is useful in treating infections caused by multiresistant bacteria. Daptomycin is approved for use in adults in the US for skin and skin structure infections caused by Gram-positive infections, right-sided S. aureus endocarditis, and S. aureus bacteriemia. A major drawback that has to be considered if it is used as aerosol treatment is that it binds avidly to pulmonary surfactant, and therefore cannot be used in the treatment of pneumonia as it is in aerosol form. ${ }^{38}$ However, there seems to be a difference in working daptomycin on hematogenous pneumonia. ${ }^{39}$

If one day these products reach the production arena, time of administration is an essential factor for cost-time effectiveness. Time-consuming aerosol administration can cause adverse effects, such as cough. ${ }^{8}$ Finally, cup design $\mathrm{D}$ is suggested as the most effective cup for lowering the droplet size $(2.30 \mu \mathrm{m})$ when considering a higher loading level $(8 \mathrm{~mL})$. In our future experiments, we will investigate the effect of different mouthpiece designs with the best combination of residual cup design and residual cup filling for each drug. In addition, we will record the time of administration and droplet size production with the different mouthpiece designs.

\section{Disclosure}

The authors report no conflicts of interest in this work.

\section{References}

1. Zarogoulidis P, Chatzaki E, Porpodis K, et al. Inhaled chemotherapy in lung cancer: future concept of nanomedicine. Int J Nanomedicine. 2012;7:1551-1572.

2. Zarogoulidis P, Hohenforst-Schmidt W, Darwiche K, et al. 2-diethylaminoethyl-dextran methyl methacrylate copolymer nonviral vector: still a long way toward the safety of aerosol gene therapy. Gene Ther. 2013;20(10):1022-1028.

3. Zarogoulidis P, Darwiche K, Hohenforst-Schmidt W, et al. Inhaled gene therapy in lung cancer: proof-of-concept for nano-oncology and nanobiotechnology in the management of lung cancer. Future Oncol. 2013;9(8):1171-1194. 
4. Zarogoulidis P, Eleftheriadou E, Sapardanis I, et al. Feasibility and effectiveness of inhaled carboplatin in NSCLC patients. Invest New Drugs. 2012;30(4):1628-1640.

5. Patel RB, Smaldone GC, Cuccia AD, Strachan P. In vitro delivery of aerosolized treprostinil via modern mechanical ventilation. J Aerosol Med Pulm Drug Deliv. 2013;26(4):200-207.

6. Zarogoulidis P, Kioumis I, Ritzoulis C, et al. New insights in the production of aerosol antibiotics. Evaluation of the optimal aerosol production system for ampicillin-sulbactam, meropenem, ceftazidime, cefepime and piperacillin-tazobactam. Int J Pharm. 2013;455(1-2):182-188.

7. Zarogoulidis P, Kioumis I, Porpodis K, et al. Clinical experimentation with aerosol antibiotics: current and future methods of administration. Drug Des Devel Ther. 2013;7:1115-1134.

8. Zarogoulidis P, Darwiche K, Yarmus L, et al. Defense mechanisms of the respiratory system and aerosol production systems. Med Chem. 2014;10(2):123-136.

9. Miller JK, Neubig R, Clemons CB, et al. Nanoparticle deposition onto biofilms. Ann Biomed Eng. 2013;41(1):53-67.

10. Ma B, Darquenne C. Aerosol deposition characteristics in distal acinar airways under cyclic breathing conditions. J Appl Physiol (1985). 2011;110(5):1271-1282.

11. Clay MM, Pavia D, Newman SP, Clarke SW. Factors influencing the size distribution of aerosols from jet nebulisers. Thorax. 1983;38(10): 755-759.

12. Newman SP, Pellow PG, Clay MM, Clarke SW. Evaluation of jet nebulisers for use with gentamicin solution. Thorax. 1985;40(9):671-676.

13. Kendrick AH, Smith EC, Wilson RS. Selecting and using nebuliser equipment. Thorax. 1997;52(Suppl 2):S92-S101.

14. Kendrick AH, Smith EC, Denyer J. Nebulizers - fill volume, residual volume and matching of nebulizer to compressor. Respir Med. 1995; 89(3):157-159.

15. Kwok PC, Trietsch SJ, Kumon M, Chan HK. Electrostatic charge characteristics of jet nebulized aerosols. J Aerosol Med Pulm Drug Deliv. 2010;23(3):149-159.

16. Hoffmann N, Duft D, Kiselev A, Leisner T. Contact freezing efficiency of mineral dust aerosols studied in an electrodynamic balance: quantitative size and temperature dependence for illite particles. Faraday Discuss. 2013;165:383-390.

17. Davis JM, Davies IA. Some physico-chemical characteristics of the antigens of Ehrlich ascites-tumour cells. Biochem Soc Trans. 1980;8(4): 436-437.

18. Buttini F, Miozzi M, Balducci AG, et al. Differences in physical chemistry and dissolution rate of solid particle aerosols from solution pressurised inhalers. Int J Pharm. 2014;465(1-2):42-51.

19. Chen C, Zhao B, Cui W, Dong L, An N, Ouyang X. The effectiveness of an air cleaner in controlling droplet/aerosol particle dispersion emitted from a patient's mouth in the indoor environment of dental clinics. $J R$ Soc Interface. 2010;7(48):1105-1118.

20. Lelong N, Vecellio L, Sommer de Gelicourt Y, Tanguy C, Diot P, Junqua-Moullet A. Comparison of numerical simulations to experiments for atomization in a jet nebulizer. PLOS ONE. 2013;8(11):e78659.

21. Wu C, Lee D, Zachariah MR. Aerosol-based self-assembly of nanoparticles into solid or hollow mesospheres. Langmuir. 2010;26(6):4327-4330.

22. Labiris NR, Dolovich MB. Pulmonary drug delivery. Part I: physiological factors affecting therapeutic effectiveness of aerosolized medications. Br J Clin Pharmacol. 2003;56(6):588-599.
23. Zarogoulidis P, Papanas N, Kouliatsis G, Spyratos D, Zarogoulidis K, Maltezos E. Inhaled insulin: too soon to be forgotten? J Aerosol Med Pulm Drug Deliv. 2011;24(5):213-223.

24. Darwiche K, Zarogoulidis P, Karamanos NK, et al. Efficacy versus safety concerns for aerosol chemotherapy in non-small-cell lung cancer: a future dilemma for micro-oncology. Future Oncol. 2013;9(4): 505-525.

25. Zarogoulidis P, Giraleli C, Karamanos NK. Inhaled chemotherapy in lung cancer: safety concerns of nanocomplexes delivered. Ther Deliv. 2012;3(9):1021-1023.

26. Zarogoulidis P, Petridis D, Ritzoulis C, et al. Internal mouthpiece designs as a future perspective for enhanced aerosol deposition. Comparative results for aerosol chemotherapy and aerosol antibiotics. Int J Pharm. 2013;456(2):325-331.

27. Zarogoulidis P, Darwiche K, Huang H, et al. Time recall; future concept of chronomodulating chemotherapy for cancer. Curr Pharm Biotechnol. 2013;14(6):632-642.

28. Zaric B, Stojsic V, Tepavac A, et al. Adjuvant chemotherapy and radiotherapy in the treatment of non-small cell lung cancer (NSCLC). J Thorac Dis. 2013;5(Suppl 4):S371-S377.

29. Boukovinas I, Tsakiridis K, Zarogoulidis P, et al. Neo-adjuvant chemotherapy in early stage non-small cell lung cancer. $J$ Thorac Dis. 2013;5(Suppl 4):S446-S448.

30. Maiz L, Canton R, Mir N, Baquero F, Escobar H. Aerosolized vancomycin for the treatment of methicillin-resistant Staphylococcus aureus infection in cystic fibrosis. Pediatr Pulmonol. 1998;26(4):287-289.

31. Park CW, Li X, Vogt FG, et al. Advanced spray-dried design, physicochemical characterization, and aerosol dispersion performance of vancomycin and clarithromycin multifunctional controlled release particles for targeted respiratory delivery as dry powder inhalation aerosols. Int J Pharm. 2013;455(1-2):374-392.

32. Nettey H, Haswani D, Oettinger CW, D'Souza MJ. Formulation and testing of vancomycin loaded albumin microspheres prepared by spraydrying. J Microencapsul. 2006;23(6):632-642.

33. Zarogoulidis P, Petridis D, Ritzoulis C, et al. Further experimentation of inhaled; LANTUS, ACTRAPID and HUMULIN with todays' production systems. Int J Pharm. 2013;458(1):39-47.

34. Prober CG, Walson PD, Jones J; Committee on Infectious Diseases and Committee on Drugs. Technical report: precautions regarding the use of aerosolized antibiotics. Pediatrics. 2000;106(6):E89.

35. Swaney SM, Aoki H, Ganoza MC, Shinabarger DL. The oxazolidinone linezolid inhibits initiation of protein synthesis in bacteria. Antimicrob Agents Chemother. 1998;42(12):3251-3255.

36. Brickner SJ, Hutchinson DK, Barbachyn MR, et al. Synthesis and antibacterial activity of U-100592 and U-100766, two oxazolidinone antibacterial agents for the potential treatment of multidrugresistant gram-positive bacterial infections. J Med Chem. 1996;39(3): 673-679.

37. Moellering RC Jr. Vancomycin: a 50-year reassessment. Clin Infect Dis. 2006;42(Suppl 1):S3-S4.

38. Baltz RH. Daptomycin: mechanisms of action and resistance, and biosynthetic engineering. Curr Opin Chem Biol. 2009;13(2):144-151.

39. Henken S, Bohling J, Martens-Lobenhoffer J, et al. Efficacy profiles of daptomycin for treatment of invasive and noninvasive pulmonary infections with Streptococcus pneumoniae. Antimicrob Agents Chemother. 2010;54(2):707-717.
Drug Design, Development and Therapy

\section{Publish your work in this journal}

Drug Design, Development and Therapy is an international, peerreviewed open-access journal that spans the spectrum of drug design and development through to clinical applications. Clinical outcomes, patient safety, and programs for the development and effective, safe, and sustained use of medicines are a feature of the journal, which

\section{Dovepress}

has also been accepted for indexing on PubMed Central. The manuscript management system is completely online and includes a very quick and fair peer-review system, which is all easy to use. Visit $\mathrm{http}: / /$ www.dovepress.com/testimonials.php to read real quotes from published authors.

Submit your manuscript here: http://www.dovepress.com/drug-design-development-and-therapy-journal 